\title{
The Effects of the Different Frequencies of Whole-Body Vibration after a Strenuous Activity on Blood Lactic Acid
}

\author{
${ }^{1}$ Mohammad Rashidi*, ${ }^{1}$ Mahsa Sedaghat, ${ }^{2}$ Manizheh Shahvaranian
}

${ }^{1}$ Department of Physical Education and Sport Sciences, Semnan Branch, Islamic Azad University, Semnan, Iran.

${ }^{2}$ Department of Physical Education, Mehdi Shahr Office of Education, Mehdi Shahr, Iran.

\begin{abstract}
Background. Fatigue has an undesirable effect on the continued exercise performance and decreases athlete's activity. Fast lactic acid disposed is high of importance for athletes.

Objectives. Therefore, the present article determines the effects of the different frequencies of whole-body vibration after a strenuous activity on blood lactic acid.

Methods. 60 athletes were chosen from selected athletes of provincial championship through bruce test. The athletes randomly were divided into four groups of 15 participating in the initial recovery scheme after strenuous exercise (Cunningham test). The first group did initial passive/ inactive recovery that the subjects sat on a chair after exercise and the second to fourth did initial 15 minutes active retrieval on the vibration platform at different rate /with different speed. Their blood lactic acid was checked in three phases by manual lactometer (before activity, immediately after the activity, 15 minutes recovery period the initial situation).

Results. The result of this research indicated that the average level of lactic acid immediately after activity to before activity among 4 groups was significantly different $(\mathrm{P}=0.006)$. decrease in lactic acid 15 minutes after the initial state recovery to immediately after that, was significant in all groups $(\mathrm{p}<0 / 001)$. In initial recovery with $20 \mathrm{HZ} \mathrm{WBV}$ at amplitude of $5 \mathrm{~mm}$ lactic acid repelling excretion was the most.

Conclusion. In general, it is showed that to excrete the lactic acid after exhausting and intense activity active initial state recovery scheme with whole- body vibration (WBV) at $20 \mathrm{HZ}$ and on amplitude of $5 \mathrm{~mm}$ had much more useful effects on reducing lactic acid after exhausting and intense activities than other schemes. Hence, active initial recovery with whole - body vibration at mentioned rate is recommended to remove immediately the lactic acid from the body after intense anaerobic exercise.
\end{abstract}

KEY WORDS: Blood Lactate, Fatigue, Recovery, Whole-Body Vibration, Exhaustive Exercise.

\section{INTRODUCTION}

Intense exercise leads to production of lactic acid and hydrogen ions in muscles which reduce the intracellular PH $(1,2)$. This acidosis harms muscle contraction and glycolytic enzyme activities, thus reducing the athletic performance (2). It is vital for athlete to rapidly remove lactic acid from the body, especially when the repetition is considered $(3,4)$. Generally, the blood lactic acid removal is accelerated by active recovery (4-18).

Whole-body vibration (WBV), as a physical activity helps in muscle strengthening, cardiovascular fitness, increased oxygen consumption and neuromuscular factors

*. Corresponding Author:

Mohammad Rashidi

E-mail:mrashidi48@yahoo.com 
affecting fatigue mechanism (19-22). In a study, it was concluded that vibration before and after exercise helps reduce fatigue and accelerates recovery (23). A study was conducted to evaluate the effects of WBV during the recovery after intense exhausting activities. The results revealed that both low and high repetition in vibration exercise during the recovery period after exhausting activities cannot cause improvement. However, high reps in vibration may further facilitate the process of oxygen consumption to return to the initial levels in the primary recovery (24).

Another study concluded that oxygen consumption is significantly increased in young and older adults by vibration; nevertheless, such an increase in oxygen consumption by WBW may act as incentives to improve cardiovascular fitness (25).

Another study showed that WBV exercise improves cardiovascular endurance and plays an important role in neuromuscular mechanism (26). The other study considered dynamic stretching as the best way to remove lactic acid from the body after intense exhausting activity (27). Other studies argued that severe vibration is not useful in the recovery phase (28), WBV is not efficient enough compared to natural recovery (29), passive vibration is effective to reduce heart rate (30), high-speed WBV with higher amplitude is more useful (31), and lowspeed vibration cannot be effective for lactic acid excretion (32).

Results of studies conducted in this area are contradictory in some cases and there are few studies on the effects of WBV on the amount of lactic acid removed from the body. Therefore, this study aimed to investigate the effect of WBV with various speeds on the amount of lactic acid removal.

\section{MATERIALS AND METHODS}

Participants. 60 male athlete students selected based on the 7-step Bruce protocol and divided into four 15 -member groups by simple random sampling. This number of samples was chosen from selected athletes of provincial championship through bruce test. The athletes randomly were divided into four groups of 15 participating in the initial recovery scheme after strenuous exercise (Cunningham test). The first group did initial passive/ inactive recovery that the subjects sat on a chair after exercise and the second to fourth did initial 15 minutes active retrieval on the vibration platform at different rate /with different speed. Their blood lactic acid was checked in three phases by manual lactometer (before activity, immediately after the activity, 15 minutes recovery period the initial situation).

Training Protocol. The intense exhausting exercise considered in this study was the Cunningham test in. After the Cunningham test, all groups had a 15-minute recovery and lactic acid was measured in three phases (before the test, immediately after the test, 15 minutes after the recovery). The recovery period for groups was as:

Group A: inactive recovery (seated);

Group B: active recovery with WBV at $10 \mathrm{~Hz}$ an amplitude of $5 \mathrm{~mm}$;

Group C: active recovery with WBV at $20 \mathrm{~Hz}$ an amplitude of $5 \mathrm{~mm}$;

Group D: active recovery with WBV at $30 \mathrm{~Hz}$ an amplitude of $5 \mathrm{~mm}$.

Statistical Analysis. To analyze the obtained data, some tests were conducted including ShapiroWilk, ANOVA (or Kruskal-Wallis), and Tukey post hoc. Statistical analysis was performed by SPSS18 software at significant level $\mathrm{p}<0.05$.

\section{RESULTS}

Some demographic characteristic is shown in table 1. Table 2 shows resting heart rate and immediately after exercise as well as exercise time in studied groups. There was a significant difference between the lactic acid level at rest $(p=0.026)$, immediately after the exercise $(\mathrm{p}<0.001)$ and 15 minutes after recovery $(\mathrm{p}<0.001)$ (Table 3). Lactic acid increased immediately after the exercise compared to before the exercise. There was a significant different in lactic acid level immediately after the exercise and before the exercise in the four groups ( $p=0.006)$ (Table 4). The increase in lactic acid immediately after the exercise compared to before the exercise was higher for group B than group A $(p=0.007)$. No significant difference was observed in other groups. 
Table 1. Demographic characteristic (Mean $\pm \mathrm{SD})$.

\begin{tabular}{ccc}
\hline Group & Age (year) & BMI $(\mathrm{kg} / \mathrm{m} 2)$ \\
\hline A & $23.7 \pm 1.5$ & $23.7 \pm 3.4$ \\
\hline B & $23.6 \pm 1.8$ & $23.5 \pm 2.1$ \\
\hline C & $23.1 \pm 1.6$ & $22.9 \pm 1.4$ \\
\hline D & $22.9 \pm 1.4$ & $23.5 \pm 2.3$ \\
\hline
\end{tabular}

A: inactive recovery (seated); B: active recovery with $\mathrm{WBV}$ at $10 \mathrm{~Hz}$ an amplitude of $5 \mathrm{~mm}$; $\mathbf{C}$ : active recovery with $\mathrm{WBV}$ at $20 \mathrm{~Hz}$ an amplitude of $5 \mathrm{~mm}$; D: active recovery with $\mathrm{WBV}$ at $30 \mathrm{~Hz}$ an amplitude of $5 \mathrm{~mm}$.

Table 2: Resting and exercise heart rate and exercise time in studies groups (Mean $\pm \mathrm{SD}$ ).

\begin{tabular}{cccc}
\hline Group & $\begin{array}{c}\text { Resting } \\
\text { heart rate }\end{array}$ & $\begin{array}{c}\text { exercise } \\
\text { Heart rate }\end{array}$ & $\begin{array}{c}\text { Exercise } \\
\text { time }(\mathrm{S})\end{array}$ \\
\hline A & $70 \pm 5$ & $172 \pm 6$ & $400 \pm 40.8$ \\
\hline B & $68 \pm 3$ & $174 \pm 5$ & $410 \pm 42.6$ \\
\hline C & $69 \pm 4$ & $172 \pm 5$ & $419 \pm 45.7$ \\
\hline D & $70 \pm 4$ & $173 \pm 13$ & $412 \pm 55$ \\
\hline
\end{tabular}

A: inactive recovery (seated); B: active recovery with WBV at $10 \mathrm{~Hz}$ an amplitude of $5 \mathrm{~mm}$; $\mathbf{C}$ : active recovery with WBV at $20 \mathrm{~Hz}$ an amplitude of $5 \mathrm{~mm}$; D: active recovery with $\mathrm{WBV}$ at $30 \mathrm{~Hz}$ an amplitude of $5 \mathrm{~mm}$.

There was a significant different in lactic acid level 15 minutes after recovery and before the exercise in the four groups ( $<<0.001)$ (Table 4), so that the increase in lactic acid levels 15 minutes after recovery compared with before exercise was higher in A $(\mathrm{p}<0.001)$, B ( $\mathrm{p}<$ $0.001)$, and $\mathrm{D}(\mathrm{p}<0.001)$ than the $\mathrm{C}$. This increase was also greater in $\mathrm{A}$ than $\mathrm{D}(\mathrm{p}=$ 0.001). Other groups were not significantly different.

There was a significant different in lactic acid level 15 minutes after recovery compared to $b$ immediately after the exercise in the four groups ( $\mathrm{p}<0.001$ ) (Table 4), so that, except for B and D $(\mathrm{p}=0.986)$, the difference was significant $(\mathrm{p}<0.001)$ for other cases. The reduction was higher in group $\mathrm{C}$ than other groups.

Table 3. Lactic acid (mmol/L) (Mean \pm SD).

$15 \mathrm{~min}$
Recovery

\begin{tabular}{cccc}
\hline $\mathbf{A}$ & $3.75 \pm 0.58$ & $11.81 \pm 1.52$ & $10.02 \pm 1.38$ \\
\hline $\mathbf{B}$ & $4.11 \pm 0.77$ & $13.33 \pm 0.88$ & $9.53 \pm 0.92$ \\
\hline $\mathbf{C}$ & $4.05 \pm 0.25$ & $12.99 \pm 0.50$ & $6.07 \pm 0.53$ \\
\hline $\mathbf{D}$ & $4.37 \pm 0.40$ & $12.78 \pm 0.51$ & $9.08 \pm 0.91$
\end{tabular}

A: inactive recovery (seated); B: active recovery with $\mathrm{WBV}$ at $10 \mathrm{~Hz}$ an amplitude of $5 \mathrm{~mm}$; $\mathbf{C}$ : active recovery with WBV at $20 \mathrm{~Hz}$ an amplitude of $5 \mathrm{~mm}$; D: active recovery with $\mathrm{WBV}$ at $30 \mathrm{~Hz}$ an amplitude of $5 \mathrm{~mm}$.

Table 4. Acute and recovery response of lactic acid to exercise test (Mean \pm SD).

\begin{tabular}{cccc}
\hline Group & $\begin{array}{c}\text { Acute response to exercise } \\
\text { respect to pretest }\end{array}$ & $\begin{array}{c}\mathbf{1 5} \text { min recovery respect to } \\
\text { pretest }\end{array}$ & $\begin{array}{c}\text { Delta acute to 15 min response to } \\
\text { exercise test }\end{array}$ \\
\hline $\mathbf{A}$ & $8.05 \pm 1.35$ & $6.27 \pm 1.32$ & $1.79 \pm 0.65$ \\
\hline $\mathbf{B}$ & $9.22 \pm 1.07$ & $5.41 \pm 1.07$ & $3.81 \pm 0.80$ \\
\hline $\mathbf{C}$ & $8.93 \pm 0.41$ & $2.02 \pm 0.53$ & $6.91 \pm 0.60$ \\
\hline $\mathbf{D}$ & $8.41 \pm 0.65$ & $4.71 \pm 0.95$ & $3.7 \pm 1.22$ \\
\hline $\mathbf{p}$ & 0.006 & $\mathrm{P}<0.001$ & $\mathrm{P}<0.001$ \\
\hline
\end{tabular}

A: inactive recovery (seated); B: active recovery with $\mathrm{WBV}$ at $10 \mathrm{~Hz}$ an amplitude of $5 \mathrm{~mm}$; $\mathbf{C}$ : active recovery with $\mathrm{WBV}$ at $20 \mathrm{~Hz}$ an amplitude of $5 \mathrm{~mm}$; D: active recovery with WBV at $30 \mathrm{~Hz}$ an amplitude of $5 \mathrm{~mm}$.

\section{DISCUSSION}

As measured, the mean lactic acid concentration for the inactive group was 3.75 $\mathrm{mmol} / \mathrm{lit}$ at rest. After the Cunningham test (the maximum intense exercise) which is a short-term anaerobic test, the concentration of lactic acid in the blood was increased to $11.81 \mathrm{mmol} / \mathrm{lit}$. Then, this group experienced an inactive recovery (seated) and after a 15-minute recovery, the lactic acid concentration was again measured showing a mean of $10.02 \mathrm{mmol} / \mathrm{lit}$.

In the active group, the average concentration of lactic acid at rest was 4.37, 4.05, and 4.11 mmol per liter at WBV with 10,20 , and $30 \mathrm{~Hz}$ speed, respectively. After the Cunningham test, the average values increased to $12.78,12.99$, and 13.33 mmol per liter, respectively. Then the three groups passed the recovery program using WBV and 15 minutes after the recovery, the 
average concentrations of lactic acid in the blood were measured as $9.08,6.07$, and $9.53 \mathrm{mmol}$ per liter. As a result, there was a significant difference between the lactic acid level at rest ( $p$ $=0.026)$, immediately after the exercise $(\mathrm{p}<$ $0.001)$ and 15 minutes after recovery $(\mathrm{p}<0.001)$

In addition, there was a significant difference in lactic acid level in 15 minutes after recovery for all groups while this value was highest for A and lowest for $\mathrm{C}$.

According to findings in this study, active recovery is much more useful than inactive one and this is consistent with findings of other researches (4-18).

Results obtained by this study are consistent with the findings of some other studies examining the effects of vibration study (19-22) and not consistent with other studies (24, 27-29). This may be due to small sample size or different approaches. So a study with a larger sample size is recommended. The results showed that low- or very high speed vibrations do not result in faster disposal of lactic acid in the body which are consistent with some studies $(31,32)$. The reason for this may be the fact that very high speed vibration is an intense activity that not only does not reduce the lactic acid levels, but also results in higher accumulation of lactic acid.

The mean reduction in the level of lactic acid immediately after exercise compared to 15 minutes after recovery in inactive and active groups at 10, 20, and $30 \mathrm{~Hz}$ speed with amplitude of $5 \mathrm{~mm}$ was $3.70,6.91,3.81$, and $1.79 \mathrm{mmol}$ per liter, indicating a significant difference $(\mathrm{P}<0.001)$. As obvious, the average reduction in $\mathrm{C}$ was significantly higher $(\mathrm{P}<$ 0.001) than other groups suggesting that active recovery with $\mathrm{WBV}$ at $20 \mathrm{~Hz}$ and amplitude of 5 $\mathrm{mm}$ was more beneficial than other programs for the reduction of lactic acid after an intense exhausting exercise. This might be useful for fields with short-break matches (such as wrestling, martial arts, etc.) to have an active recovery using vibration at the specified speed to faster remove lactic acid.

\section{CONCLUSION}

Generally, based on the findings, we can conclude that an active recovery with WBV at a speed of $20 \mathrm{~Hz}$ and amplitude of $5 \mathrm{~mm}$ may have more favorable effects on lactic acid removal after an intense exhausting exercise. Therefore, to faster remove the lactic acid from the body after an intense anaerobic activity, an active recovery with whole-body vibration at the specified speed is recommended.

\section{APPLICABLE REMARKS}

- The Active recovery is disabled in the amount of lactic acid from the blood and is more effectively.

- The recovery is enabled with whole body vibration at $20 \mathrm{~Hz}$ and amplitude of $5 \mathrm{Mm}$ desirable Terry in the amount of lactic acid after a grueling and intense activity will be.

\section{REFERENCES}

1. Astrand P, Hultman E, Juhlin-Dannfelt A. Disposal of lactate during and after streneus exercise in human. J Appl Physiol. 1986;11: 338-43.

2. Hermansen L. Effect of acidosis on skeletal muscle performance during maximal exercise in man. Bull Europ Physiopath Resp. 1979;15:229-38.

3. McMaster W, Stoddard T, Duncan W. Enhancement of blood lactate clearance following maximal swimming. Effect of velocity of recovery swimming. Am J Sports Med. 1986;17:472-7.

4. Monedero J, Donne B. Effect of recovery interventions on lactate removal and subsequent performance. Int J Sports Med. 2000;21: 593-7. 
5. Ahmaidi S, Granier P, Taoutaou Z. Effects of active recovery on plasma lactate and anaerobic power following repeated intensive exercise. Med Sci Sports Exerc. 1996;28:450-6.

6. Bond V, Adams R, Tearney R. Effects of active and passive recovery on lactate removal and subsequent isokinetic muscle function. J Sports Med Phys Fitness. 1991;31:357-61.

7. Gupta S, Goswami A, Sadhukhan A.K. Comparative study of lactate removal in short term massage of extremities, active recovery and a passive recovery period after supramaximal exercise sessions. Int $\mathbf{J}$ Sports Med. 1996;17:106-10.

8. Hermansen L, Stensvold I. Production and removal of lactate during exercise in man. Acta Physiol Scand. 1972;86: 191-201.

9. Stamford B A, Weltman A, Moffatt R. Exercise recovery above and below anaerobic threshold following maximal work. J Appl Physiol. 1981;51: 840-44.

10.Weltman A, Stamford B.A, Moffatt R.J. Exercise recovery, lactate removal, and subsequent performance. Res Q. 1977;48:786-96.

11.Martin N.A. The comparative effects of sports massage, active recovery and rest in promoting blood lactate clearance after super maximal leg exercise.j Atl train.jan. 1998;33(1):30-35.

12.Baldar C. Lactate removal during active recovery related to the individual anaerobic and vntilatory thresholds in soccer players.Eu.r J APPL physiol . 2005;94(1-2):220.

13.Gemada N. Effect of combined active recovery from supramaximal exercise on blood lactate disappearance in trained and untrained man .Int sport Med. 2005;26(10): 874-80.

14.Sieqler J.C. active and passive recovery and acid -base kinetics following multiple bouts of intense exercise to exhaustion.Int J. Nutr.exere Metab. 2006;16(1): 92-107.

15. Spencer M, Bishop D, Dawson B, Goodman C, Duffield R. pencer metabolism and performance in repeated cycle sprint: active versus passive recovery. Med Sci Sport Exerc. 2006;38(8):1422-9.

16.Bonen A.N. Lactic acid removal rate during active recovery.J sports med physical fitness Jun. 1998;28(2): 115-123.

17.Osawa Y, Oguma Y. Effects of vibration on flexibility: a meta-analysis. J Musculoskelet Neuronal Interact. 2013;13(4):442-53.

18.Koh H.W, Cho S.H, Kim C.Y, Cho B.J, Kim J.W, Bo K.H. Effects of vibratory stimulations on maximal voluntary isometric contraction from delayed onset muscle soreness. J Phys Ther Sci. 2013;25(9):1093-5.

19.Cochrane D.J, Sartor F, Winwood K, Stannard S.R, Narici M.V, Rittweger J. A comparison of the physiologic effects of acute whole-body vibration exercise in young and older people. Arch Phys Med Rehabil. 2008;89(5): 815-21.

20.Perret C, Muelle G. Impact of low-intensity isocapnic hyperpnoea on blood lactate disappearance after exhaustive arm exercise. Br J Sports Med. 2007;41(9): 588-91.

21.Rittweger J, Beller G, Felsenberg D. Acute physiological effects of exhaustive whole-body vibration exercise in man. Clin Physiol. 2000:20(2): 134-42.

22.Cardinale M, Wakeling J. Whole body vibration exercise: are vibrations good for you? Br J Sports Med. 2005;39(9):585-9.

23.Kosar A.C, Candow D.G, Putland J.T. Potential beneficial effects of whole-body vibration for muscle recovery after exercise. J Strength Cond Res. 2012;26(10):2907-11.

24.Cheng C.F, Hsu W.C, Lee C.L, Chung P.K. Effects of the different frequencies of whole-body vibration during the recovery phase after exhaustive exercise. J Sports Med Phys Fitness. 2010;50(4): 407-15.

25.Cochrane D.J, Sartor F, Winwood K, Stannard S.R, Narici M.V, Rittweger J. A comparison of the physiologic effects of acute whole-body vibration exercise in young and older people. Arch Phys Med Rehabil. 2008;89(5): 815-21.

26.Rittweger J, Beller G, Felsenberg D. Acute physiological effects of exhaustive whole-body vibration exercise in man. Clin Physiol. 2000. 
27.Miladi I, Temfemo A, Mandengué S.H, Ahmaidi S. Effect of recovery mode on exercise time to exhaustion, cardiorespiratory responses, and blood lactate after prior, intermittent supramaximal exercise. J Strength Cond Res. 2011;25(1): 205-10.

28.Edge J, Mündel T, Weir K, Cochrane D.J. The effects of acute whole body vibration as a recovery modality following high-intensity interval training in well-trained, middle-aged runners. Eur $\mathrm{J}$ Appl Physiol. 2009;105(3): 421-8.

29.Manimmanakorn N, Ross J.J, Manimmanakorn A, Lucas S.J, Hamlin M.J. Effect of whole-body vibration therapy on performance recovery. Int J Sports Physiol Perform. 2015;10(3): 388-95.

30.Sañudo B, César-Castillo M, Tejero S, Nunes N, de Hoyo M, Figueroa A. Cardiac autonomic response during recovery from a maximal exercise using whole body vibration. Complement Ther Med. 2013;21(4): 294-9.

31. Adams J.B, Edwards D, Serravite D.H, Bedient A.M, Huntsman E, Jacobs K.A, Del Rossi G, Roos B.A, Signorile J.F. Optimal frequency, displacement, duration, and recovery patterns to maximize power output following acute whole-body vibration. J Strength Cond Res. 2009;23(1):237-45.

32. Carrasco L, Sañudo B, de Hoyo M, Pradas F, Da Silva M.E. Effectiveness of low-frequency vibration recovery method on blood lactate removal, muscle contractile properties and on time to exhaustion during cycling at VO2max power output. Eur J Appl Physiol. 2011;111(9): 2271-9. 